\title{
Racial Disparities in Access to and Outcomes of Kidney Transplantation in Children, Adolescents, and Young Adults: Results From the ESPN/ERA-EDTA (European Society of Pediatric Nephrology/European Renal Association-European Dialysis and Transplant Association) Registry
}

\author{
Lidwien A. Tjaden, MD, ${ }^{1,2}$ Marlies Noordzij, PhD, ${ }^{1}$ Karlijn J. van Stralen, $P h D,{ }^{1}$ \\ Claudia E. Kuehni, MD, ${ }^{3}$ Ann Raes, MD, PhD, ${ }^{4}$ Elisabeth A.M. Cornelissen, MD, PhD, ${ }^{5}$ \\ Catherine O'Brien, $M D, P h D,{ }^{6}$ Fotios Papachristou, $M D, P h D,{ }^{7}$ \\ Franz Schaefer, MD, PhD, ${ }^{8}$ Jaap W. Groothoff, MD, $P h D,{ }^{2}$ and \\ Kitty J. Jager, MD, PhD, ${ }^{1}$ on behalf of the ESPN/ERA-EDTA Registry Study Group*
}

\begin{abstract}
Background: Racial disparities in kidney transplantation in children have been found in the United States, but have not been studied before in Europe.

Study Design: Cohort study.

Setting \& Participants: Data were derived from the ESPN/ERA-EDTA Registry, an international pediatric renal registry collecting data from 36 European countries. This analysis included 1,134 young patients (aged $\leq 19$ years) from 8 medium- to high-income countries who initiated renal replacement therapy (RRT) in 2006 to 2012.

Factor: Racial background.

Outcomes \& Measurements: Differences between racial groups in access to kidney transplantation, transplant survival, and overall survival on RRT were examined using Cox regression analysis while adjusting for age at RRT initiation, sex, and country of residence.

Results: 868 (76.5\%) patients were white; 59 (5.2\%), black; $116(10.2 \%)$, Asian; and 91 (8.0\%), from other racial groups. After a median follow-up of 2.8 (range, 0.1-3.0) years, we found that black (HR, $0.49 ; 95 \% \mathrm{Cl}$, $0.34-0.72$ ) and Asian (HR, $0.54 ; 95 \% \mathrm{Cl}, 0.41-0.71$ ) patients were less likely to receive a kidney transplant than white patients. These disparities persisted after adjustment for primary renal disease. Transplant survival rates were similar across racial groups. Asian patients had higher overall mortality risk on RRT compared with white patients (HR, 2.50; 95\% Cl, 1.14-5.49). Adjustment for primary kidney disease reduced the effect of Asian background, suggesting that part of the association may be explained by differences in the underlying kidney disease between racial groups.

Limitations: No data for socioeconomic status, blood group, and HLA profile.

Conclusions: We believe this is the first study examining racial differences in access to and outcomes of kidney transplantation in a large European population. We found important differences with less favorable outcomes for black and Asian patients. Further research is required to address the barriers to optimal treatment among racial minority groups.
\end{abstract}

INDEX WORDS: Children; adolescents; pediatric; health policy; renal replacement therapy (RRT); kidney transplantation; renal disease; racial disparities; health disparity; ethnic minority; immigrant; Europe.

$\mathbf{I}^{\mathrm{n}}$ developed countries, end-stage renal disease (ESRD) affects 5 to 10 children per million agerelated population per year. It increases mortality risk by 30 -fold compared with healthy children and induces important disabling comorbid conditions. ${ }^{1,2}$ Kidney transplantation is considered the gold standard of renal replacement therapy (RRT) among patients with chronic kidney failure because it is
From the ${ }^{1}$ ESPN/ERA-EDTA Registry, Department of Medical Informatics, Academic Medical Center; ${ }^{2}$ Department of Pediatric Nephrology, Emma Children's Hospital, Amsterdam, the Netherlands; ${ }^{3}$ Swiss Pediatric Renal Registry, Institute for Social and Preventive Medicine, University of Bern, Bern, Switzerland; ${ }^{4}$ Department of Pediatrics, Division of Pediatric Nephrology, Ghent University Hospital and Ghent University, Ghent, Belgium; ${ }^{5}$ Department of Pediatric Nephrology, Radboud University Medical Center, Nijmegen, the Netherlands; ${ }^{6}$ Birmingham Children's Hospital, Birmingham, United Kingdom; ${ }^{7}$ Department of Pediatrics, Aristotle University of Thessaloniki, Hippokratio Hospital, Thessaloniki, Greece; and ${ }^{8}$ Department of
Pediatric Nephrology, University Children's Hospital, Heidelberg, Germany.

${ }^{*}$ A list of the ESPN/ERA-EDTA Registry study group members appears in the Acknowledgements.

Address correspondence to Lidwien A. Tjaden, MD, Department of Medical Informatics, Academic Medical Center Amsterdam, the Netherlands.E-mail: l.a.tjaden@amc.uva.nl 
associated with longer life expectancy, better quality of life, and lower costs compared to long-term dialysis therapy. ${ }^{1-3}$ Health care providers therefore aim for kidney transplantation as early as possible and only initiate patients on dialysis therapy as a bridging treatment if circumstances require postponement of transplantation. However, concern has arisen regarding racial disparities in access to transplantation, especially based on studies conducted in the adult chronic kidney failure population. ${ }^{4-6}$ In the United States, black patients have lower access to and poorer outcomes of kidney transplantation than their white counterparts. $^{7}$ White patients are far more likely to receive a preemptive kidney transplant and are less likely to receive dialysis for more than 3 years before transplantation. ${ }^{8}$

Few studies have examined racial disparities in children with ESRD. Results of studies conducted in the United States and Canada parallel those performed in adult patients, with black children and adolescents having reduced access to deceased donor wait-listing ${ }^{9}$ and lower rates of preemptive and living donor transplantations compared with white children. ${ }^{10-12} \mathrm{~A}$ study performed in the Netherlands and Belgium found that children, adolescents, and young adults of non-Western origin were more often treated with hemodialysis instead of peritoneal dialysis and had decreased access to kidney transplantation compared with children, adolescents, and young adults of Western origin. ${ }^{13,14}$ However, although the total number of non-Western immigrants in Europe is growing, ${ }^{15}$ information for other European countries is lacking. We therefore aimed to assess differences in: (1) access to kidney transplantation, (2) transplant survival, and (3) overall patient survival on RRT between racial groups among children, adolescents, and young adults on RRT in Europe.

\section{METHODS}

\section{Patients}

Data were derived from the registry of the European Society of Pediatric Nephrology and the European Renal AssociationEuropean Dialysis and Transplant Association (ESPN/ERAEDTA). On an annual basis, the ESPN/ERA-EDTA Registry collects individual patient data for date of birth, sex, treatment modality at initiation of RRT, and subsequent modality changes of all young individuals requiring RRT by renal registries from 36 European countries. Twenty-two of these registries supply data for racial background. For the present study, we included data for patients 19 years or younger who initiated RRT in 2006 to 2012. To avoid confounding by economic factors in the association between race and outcomes, the analysis was restricted to medium- and high-income countries. We included countries with a gross domestic product per capita based on purchasing power parity higher than the median value for all European countries providing data for racial background (ie, US $\$ 17,140$ ). Data for purchasing power parity were derived from the databases of the World Bank Database. ${ }^{16}$ Furthermore, we only included countries with racial variation (ie, $>1$ racial group) in their patient population.
As a result, data from the following countries and periods were available and included in the analysis: Belgium (2006-2011), Czech Republic (2007-2012), Greece (2006-2012), the Netherlands (2006-2012), Portugal (2007-2012), Slovakia (2007-2012), Switzerland (2010-2012), and the United Kingdom (2006-2012)

Because this study is based on anonymized registry data, neither ethics committee approval nor informed consent from the included patients was required.

\section{Definitions}

Racial background was categorized as white, black, Asian, and other. The group Asian consisted of the subcategories South-East Asian and North-East Asian, while the group "other" included the subcategories Arabic-Middle East, North African, and mixed. Information for race was reported to the national registries by the renal units.

Patient age at initiation of RRT was categorized into 4 groups: 0 to 1,2 to 5,6 to 10 , and 11 to 19 years. Kidney diseases were grouped by primary renal disease codes for children according to the ERA-EDTA Registry coding system adapted for children. ${ }^{17}$ Furthermore, we defined focal segmental glomerulosclerosis, membranoproliferative glomerulonephritis type I and II, primary hyperoxaluria, and hemolytic uremic syndrome as primary renal diseases with a high risk for disease recurrence after kidney transplantation. ${ }^{18}$

\section{Statistical Analysis}

To explore differences in demographic and clinical characteristics between racial groups, we used $\chi^{2}$ test for categorical analysis and one-way analysis of variance for continuous variables.

Access to transplantation in the first 3 years after initiating RRT was analyzed based on the time between the initiation of RRT and the date of kidney transplantation. In case of preemptive transplantation, this time was set on 1 day. Follow-up time was censored at patient death, loss to follow-up, or the end of the study period (December 31, 2012), whichever came first. When studying access to living donor transplantation, deceased donor transplantation, transplantation with an unknown type of donor, and death can be considered as competing events because they can influence the chance of receiving a kidney from a living donor. ${ }^{19,20}$ We therefore applied the cumulative-incidence competing-risks method to study this outcome. As sensitivity analysis, we repeated this analysis including only patients 2 years and older because countries or centers may have different policies with regard to transplantation in children younger than 2 years. Five-year transplant survival after receiving a kidney transplant was calculated using the time between date of kidney transplantation and date of transplant failure (marked by retransplantation or return to dialysis therapy). Follow-up time was censored at patient death, loss to follow-up, or the end of the study period, whichever came first.

Finally, Kaplan-Meier analysis was performed to assess overall 5-year patient survival on RRT. Patient survival was defined as the time between initiation of RRT and date of death. Follow-up time was censored at loss to follow-up or end of the study period.

Cox proportional hazards analysis was performed to examine the associations between race and time from initiation of RRT to first transplantation, transplant survival, and overall patient survival on RRT, all while adjusting for potential confounders. ${ }^{21}$ As described, competing events were present when analyzing this association and a cause-specific approach was used to calculate hazard ratios (HRs) ${ }^{19,20}$ In the primary analyses, we did not adjust for primary renal disease because when racial background is considered as a biological factor, primary renal disease may be in the causal pathway in the association between racial background and the outcomes studied. In this case, it does not fulfil the criteria for confounding. ${ }^{21}$ However, additional analyses were performed 
to assess the effect of racial background other than through primary renal disease. Therefore, the variable "primary renal disease" was added to the multivariate model for analysis of patient survival, and the variable "primary renal disease with a high risk of recurrence," to the multivariate models for analysis of access to transplantation and transplant failure. Finally, we repeated the analysis for patient survival and access to transplantation using a frailty model with the variable country as a random effect in the Cox proportional hazard model.

Results are presented as HRs with 95\% confidence intervals (CIs). All analyses were performed using SPSS, version 20.0 (SPSS Inc). A 2-tailed $P=0.05$ was considered as statistically significant.

\section{RESULTS}

\section{Patients}

Data for racial background were available for 1,134 of the $1,468(77.2 \%)$ patients. Baseline characteristics of the 1,134 included patients are summarized in Table 1 . The majority of patients were white $(\mathrm{n}=868$ [76.5\%]), $59(5.2 \%)$ were black, $116(10.2 \%)$ were Asian, and $91(8.0 \%)$ were from other racial groups. The last group consisted of $14(15 \%)$ patients with an Arabic-Middle East background, 13 patients (14\%) from North Africa, and 64 patients $(70 \%)$ from mixed racial backgrounds. The distribution of country of residence was significantly different across racial groups $(P<0.001)$, especially among Asian patients, of whom $95.7 \%$ were from the United Kingdom. Black patients were more likely to have glomerulonephritis compared with white patients and patients from other racial backgrounds, who were more likely to have congenital anomalies of the kidney and

Table 1. Demographic and Clinical Characteristics of Patients (2006-2012)

\begin{tabular}{|c|c|c|c|c|c|}
\hline & $\begin{array}{c}\text { All } \\
(\mathrm{N}=1,134)\end{array}$ & $\begin{array}{c}\text { White } \\
(\mathrm{n}=\mathbf{8 6 8}[76.5 \%])\end{array}$ & $\begin{array}{c}\text { Black } \\
(\mathrm{n}=59[5.2 \%])\end{array}$ & $\begin{array}{c}\text { Asian } \\
(n=116[10.2 \%])\end{array}$ & $\begin{array}{c}\text { Other } \\
(\mathrm{n}=91[8.0 \%])\end{array}$ \\
\hline \multicolumn{6}{|l|}{ Age at RRT initiation } \\
\hline $0-1 y$ & $181(16.0)$ & $146(16.8)$ & $4(7)$ & $14(12.1)$ & 17 (19) \\
\hline $2-5 y$ & $167(14.7)$ & $128(14.7)$ & $10(17)$ & $17(14.7)$ & $12(13)$ \\
\hline $6-10 y$ & $241(21.3)$ & $179(20.6)$ & $15(25)$ & $23(19.8)$ & $24(26)$ \\
\hline $11-19 y$ & $545(48.1)$ & $415(47.8)$ & $30(51)$ & $62(53.4)$ & $38(42)$ \\
\hline Male sex & $694(61.2)$ & $541(62.3)$ & $32(54)$ & $67(57.8)$ & $54(59)$ \\
\hline \multicolumn{6}{|l|}{ Country of residence ${ }^{a}$} \\
\hline Belgium & $108(9.5)$ & $74(8.5)$ & $0(0)$ & $0(0)$ & $34(3)$ \\
\hline Czech Republic & $38(3.4)$ & $37(4.3)$ & $0(0)$ & $1(0.9)$ & $0(0)$ \\
\hline Greece & $64(5.6)$ & $54(6.2)$ & $0(0)$ & $1(0.9)$ & $9(10)$ \\
\hline Netherlands & $149(13.1)$ & $120(13.8)$ & $15(25)$ & $3(2.6)$ & $11(12)$ \\
\hline Portugal & $113(10.0)$ & $92(10.6)$ & $20(34)$ & $0(0)$ & $1(1)$ \\
\hline Slovakia & $23(2.0)$ & $16(1.8)$ & $0(0)$ & $0(0)$ & $7(8)$ \\
\hline Switzerland & $31(2.7)$ & $28(3.2)$ & $2(3)$ & $0(0)$ & $1(1)$ \\
\hline United Kingdom & $608(53.6)$ & $447(51.5)$ & $22(37)$ & $111(95.7)$ & $28(31)$ \\
\hline \multicolumn{6}{|l|}{ Primary renal disease ${ }^{a}$} \\
\hline CAKUT & $461(40.7)$ & $373(43.0)$ & $17(29)$ & $34(29.3)$ & $37(41)$ \\
\hline Glomerulonephritis & $133(11.7)$ & $92(10.6)$ & $17(29)$ & $13(11.2)$ & $11(12)$ \\
\hline Cystic kidney disease & $110(9.7)$ & $87(10.0)$ & $3(5)$ & $13(11.2)$ & $7(8)$ \\
\hline Hereditary nephropathy & $83(7.3)$ & $67(7.7)$ & $2(3)$ & $8(6.9)$ & $6(7)$ \\
\hline Ischemic kidney failure & $27(2.4)$ & $19(2.2)$ & $2(3)$ & $1(0.9)$ & $5(6)$ \\
\hline HUS & $39(3.4)$ & $33(3.8)$ & $2(3)$ & $1(0.9)$ & $3(3)$ \\
\hline Metabolic disorder & $35(3.1)$ & $28(3.2)$ & $0(0)$ & $5(4.3)$ & $2(2)$ \\
\hline Vasculitis & $15(1.3)$ & $12(1.4)$ & $2(3)$ & $1(0.9)$ & $0(0)$ \\
\hline Miscellaneous & $89(7.8)$ & $76(8.5)$ & $5(9)$ & $4(3.4)$ & $4(4)$ \\
\hline Unknown/missing & $142(12.5)$ & $81(9.3)$ & $9(15)$ & $36(31.0)$ & $16(18)$ \\
\hline $\begin{array}{l}\text { Primary renal disease with high } \\
\text { risk for recurrence } \mathrm{a}^{\mathrm{a}, \mathrm{b}}\end{array}$ & $127(12.2)$ & $91(11.6)$ & $16(32)$ & $12(15.0)$ & $8(9)$ \\
\hline \multicolumn{6}{|l|}{ Initial RRT modality } \\
\hline Peritoneal dialysis & $492(43.4)$ & $385(44.4)$ & $23(39)$ & $45(38.8)$ & $39(43)$ \\
\hline Hemodialysis & $320(28.2)$ & $228(26.3)$ & $26(44)$ & $35(30.2)$ & $31(34)$ \\
\hline Transplantation & $292(25.7)$ & $237(27.3)$ & $10(17)$ & $26(22.4)$ & $19(21)$ \\
\hline Missing/unknown & $30(2.6)$ & $18(2.1)$ & $0(0)$ & $10(8.6)$ & $2(2)$ \\
\hline Follow up time, y & $2.80[1.18-4.82]$ & 2.85 [1.23-4.83] & $2.83[1.08-4.49]$ & $1.91[0.85-4.62]$ & $2.50[1.33-5.20]$ \\
\hline
\end{tabular}

Note: Values for categorical variables are given as number (percentage); for continuous variables, as median [interquartile range]. Abbreviations: CAKUT, congenital anomalies of the kidney and urinary tract; HUS, hemolytic uremic syndrome; RRT, renal replacement therapy.

a Statistically significant different across racial groups $(P<0.05)$.

${ }^{\mathrm{b}}$ Focal segmental glomerulosclerosis, membranoproliferative glomerulonephritis type I and II, primary hyperoxaluria, and HUS. 
urinary tract (CAKUT; $P<0.001$ ). Although preemptive transplantation was nominally more common in white patients, differences between racial groups were not statistically significant $(P=0.06)$. Median follow-up ranged from 1.91 (interquartile range, 0.854.65) years in Asian patients to 2.85 (interquartile range, 1.23-4.83) years in black patients, but these differences were not statistically significant $(P=0.3)$.

Data for racial background were missing for 334 patients. Baseline characteristics for patients with and without data for racial background were significantly different regarding country of residence $(P<0.001$; Table $\mathrm{S} 1$, available as online supplementary material).

\section{Access to Transplantation}

The median time from initiation of RRT until receiving the first kidney transplant was significantly longer in black, Asian, and other patients (25.1, 23.5, and 19.4 months, respectively) compared with white patients (12.5 months, log-rank test $P=0.002)$. When we excluded preemptive transplantations, this difference was still present (20.2 months in white patients vs 35.2, 27.5, and 25.5 months in black, Asian, and other patients, respectively; log-rank test $P=0.01$ ).

A competing-risks approach was used to calculate unadjusted cumulative incidences of kidney transplantation in the first 3 years after the initiation of
RRT for the different racial groups, as shown in Fig $1 \mathrm{~A}$ to D. After 3 years, $77 \%$ of white patients and $79 \%$ of other patients had received a first transplant compared with $64 \%$ of black patients and $63 \%$ of Asian patients. Three years after the initiation of RRT, the proportion of patients living with a kidney from a living donor was $31 \%$ in white patients, $19 \%$ in black patients, $16 \%$ in Asian patients, and $18 \%$ in the group of other racial backgrounds.

To assess the association between racial background and time between initiation of RRT to first kidney transplant, a Cox proportional hazards model was used (Table 2). After adjusting for potential confounders, including age at initiation of RRT, sex, and country, both black and Asian patients were less likely than white patients to receive a first kidney transplant in the first 3 years after initiating RRT (HRs of 0.49 [95\% CI, 0.34-0.72] and 0.54 [95\% CI, 0.41-0.71], respectively). The association between race and access to transplantation, irrespective of differences in primary renal disease, was investigated by additional adjustment for primary renal disease with high risk for recurrence. This yielded very similar HRs, indicating that differences in the underlying cause of kidney disease do not explain the differences in access to kidney transplantation across racial groups. In addition, we repeated the Cox regression analyses for access to transplantation using
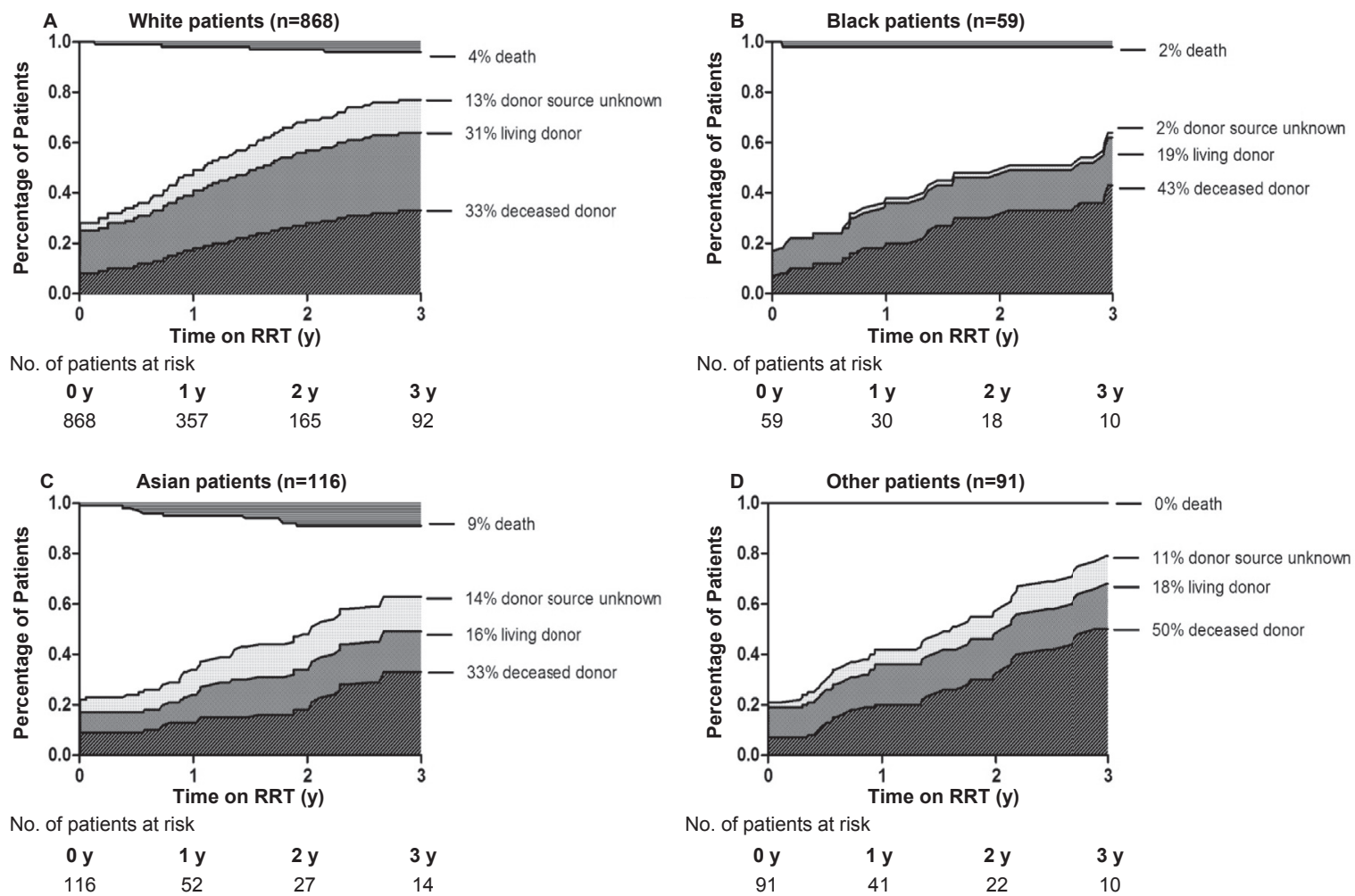

Figure 1. (A-D) Cumulative incidence of receiving a kidney transplant in the first 3 year after initiation of renal replacement therapy (RRT). 
Table 2. HRs for Access to Transplantation in the First 3 Years After the Initiation of RRT, by Racial Group

\begin{tabular}{|c|c|c|c|c|c|c|}
\hline & Unadjusted HR (95\% Cl) & $P$ & Adjusted $\mathrm{HR}^{\mathrm{a}}(95 \% \mathrm{Cl})$ & $P$ & Adjusted $\mathrm{HR}^{\mathrm{b}}(95 \% \mathrm{Cl})$ & $P$ \\
\hline White, $n=868$ & 1.00 (reference) & & 1.00 (reference) & & 1.00 (reference) & \\
\hline Black, $n=59$ & $0.64(0.44-0.92)$ & 0.02 & $0.49(0.34-0.72)$ & $<0.001$ & $0.56(0.38-0.84)$ & 0.004 \\
\hline Asian, $n=116$ & $0.69(0.52-0.90)$ & 0.007 & $0.54(0.41-0.71)$ & $<0.001$ & $0.54(0.40-0.73)$ & $<0.001$ \\
\hline Other, $\mathrm{n}=91$ & $0.83(0.63-1.09)$ & 0.2 & $0.92(0.69-1.23)$ & 0.6 & $0.93(0.68-1.27)$ & 0.9 \\
\hline
\end{tabular}

Abbreviations: $\mathrm{Cl}$, confidence interval; $\mathrm{HR}$, hazard ratio; RRT, renal replacement therapy.

aModel I: adjusted for age at RRT initiation (category), sex, and country.

${ }^{\mathrm{b}}$ Model II: adjusted for age at RRT initiation (category), sex, country, and primary renal disease with high risk for recurrence (focal segmental glomerulosclerosis, membranoproliferative glomerulonephritis type I and II, primary hyperoxaluria, and hemolytic uremic syndrome).

a frailty model with the variable country as a random effect. This analysis yielded similar results and did not change our conclusions.

Because countries or centers may have different policies with regard to transplantation in very young children, we performed sensitivity analyses including only patients 2 years and older. Excluding the youngest patients yielded higher unadjusted transplantation rates of $84 \%$ and $83 \%$ in white and other patients, respectively, compared with $71 \%$ in black patients and $70 \%$ in Asian patients. Results from the adjusted Cox regression analysis for access to transplantation were very similar to those for the total patient group (Table S2).

\section{Transplant Survival}

A total of 775 patients received a transplant in the first 5 years after the initiation of RRT. In total, 48 transplant failures occurred, of which 19 (40\%) were from a deceased donor and $5(10 \%)$ were from a living donor. For the other 24 transplant failures, donor source was unknown. The 5-year probability of transplant survival was similar among racial groups, varying from $85.0 \%$ in Asian patients to $93.0 \%$ in the groups of patients with other racial backgrounds. Also after adjustment for age at the initiation of RRT, sex, country, and primary renal disease with high risk for recurrence, transplant survival rates ware similar.

\section{Patient Survival on RRT}

Patient survival probability at 5 years after the initiation of RRT was $95.9 \%$ (95\% CI, 94.5\%96.9\%). In total, 47 patients died (36 were white; 1 , black; 9, Asian; and 1, other). Twenty eight (60\%) of them had initiated RRT before the age of 5 years, 45 (96\%) had initiated RRT with dialysis (peritoneal dialysis, $\mathrm{n}=26$ [58\%]), and only 7 had received a kidney transplant during their course of RRT ( 2 with a living donor kidney transplant). Causes of death included infections $(\mathrm{n}=13$ [28\%]), cardiovascular diseases $(n=7[15 \%])$, withdrawal from treatment $(\mathrm{n}=5 \quad[11 \%])$, malignancy $(\mathrm{n}=1 \quad[2 \%])$, and miscellaneous causes $(n=18$ [38\%]). Cause of death was missing or unknown in $3(6.4 \%)$ cases.
Kaplan-Meier analysis (Fig 2) and unadjusted Cox regression analysis (Table 3 ) showed higher mortality risk for Asian patients compared with their white counterparts. After adjustment for age at initiation of RRT, sex, and country, the mortality risk was 2.5 -fold higher for Asian patients than for white patients (HR, 2.50; 95\% CI, 1.14-5.49). The effect of race was partially taken away by additional adjustment for primary renal disease, suggesting that the association of racial background with mortality may be partially mediated by the underlying kidney disease (Table 3 ). Repeating the Cox regression analyses for patient survival using a frailty model with the variable country as a random effect yielded similar results and did not change our conclusions.

\section{DISCUSSION}

This large European study of children, adolescents, and young adults with ESRD showed that black and Asian patients were about half as likely to receive a kidney transplant as white patients, a finding that was not explained by differences in cause of kidney failure. Transplant survival rates across different racial groups were similar, but Asian patients had a 2.5-fold higher risk for death than white patients, which was partly explained by a difference in primary renal disease distribution.

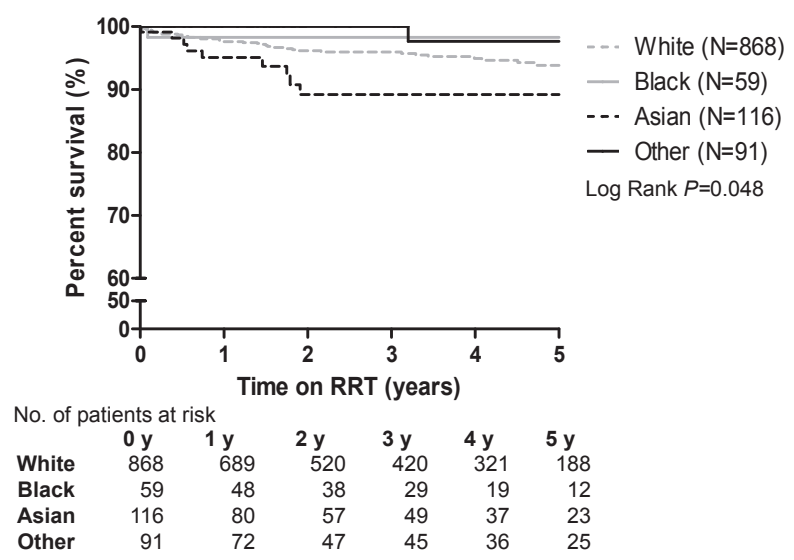

Figure 2. Kaplan-Meier curves for 5-year patient survival by racial group. Abbreviation: RRT, renal replacement therapy. 
Table 3. HRs for Mortality in the First 5 Years After the Initiation of RRT, by Racial Group

\begin{tabular}{|c|c|c|c|c|c|c|}
\hline & Unadjusted HR (95\% Cl) & $P$ & Adjusted $\mathrm{HR}^{\mathrm{a}}(95 \% \mathrm{Cl})$ & $P$ & Adjusted $\mathrm{HR}^{\mathrm{b}}(95 \% \mathrm{Cl})$ & $P$ \\
\hline White, $n=868$ & 1.00 (reference) & & 1.00 (reference) & & 1.00 (reference) & \\
\hline Black, $n=59$ & $0.41(0.06-2.99)$ & 0.4 & $0.80(0.11-6.09)$ & 0.8 & $0.53(0.07-4.16)$ & 0.6 \\
\hline Asian, $n=116$ & $2.08(1.00-4.32)$ & 0.05 & $2.50(1.14-5.49)$ & 0.02 & $1.86(0.83-4.18)$ & 0.1 \\
\hline Other, $\mathrm{n}=91$ & $0.26(0.04-1.91)$ & 0.2 & $0.28(0.04-2.13)$ & 0.2 & $0.26(0.03-1.98)$ & 0.2 \\
\hline
\end{tabular}

Abbreviations: $\mathrm{Cl}$, confidence interval; $\mathrm{HR}$, hazard ratio; $\mathrm{RRT}$, renal replacement therapy.

aModel I: adjusted for age at RRT initiation (category), sex, and country.

${ }^{\mathrm{b}}$ Model II: adjusted for age at RRT initiation (category), sex, country, and primary renal disease.

Our results regarding the disadvantage in access to kidney transplantation for black and Asian patients are in line with those of previous studies. In a study of the incidence of living and deceased donor transplantation in US Renal Data System (USRDS) data among children, adolescents, and young adults with ESRD, black and Hispanic patients had lower access to both deceased and living preemptive kidney transplantation compared with white patients, even after adjusting for individual- and neighborhood-level measures of socioeconomic status. ${ }^{22,23}$ Furthermore, Furth et $\mathrm{al}^{9}$ studied access to the kidney waiting list for black and white patients aged 0-19 years using the USRDS database. They showed that at any time point, black patients were significantly less likely than white patients to be activated on this waiting list. Similar disparities have been found in countries with universal access to health care, such as for indigenous children in Canada, Australia, and New Zea$\operatorname{land}^{10,24,25}$ and immigrant children, adolescents, and young adults in the Netherlands and Belgium. ${ }^{26}$

The causes of the observed disparities in kidney transplantation in children are thought to be multifactorial and are likely to be influenced by a complex mixture of biological, socioeconomic, and cultural factors. Because we observed a significantly higher incidence of primary renal disease known to be associated with high risk for disease recurrence (and subsequent transplant loss) in black patients, we hypothesized that this might partly explain the difference in access to transplantation. However, when we adjusted for this category of primary renal disease, the HRs did not change. This means that primary renal disease does not explain the differences in access to kidney transplantation and that additional possibly nonbiological factors are involved.

With regard to living kidney donation, it has been suggested that family members from minority groups may be less likely to be medically suitable as donors due to an increased prevalence of obesity, diabetes, and hypertension in these groups. ${ }^{27,28}$ Furthermore, part of the difference could be due to differences in patients' opinions regarding transplantation. A Dutch study looking into the willingness of accepting living donor kidney transplantation among 160 adult patients with
ESRD recently identified other nonmedical factors leading to reduced living related donation, and hence longer dialysis time, among minority groups. Those factors included different beliefs and attitudes toward donation as a result of insufficient knowledge and communication within their social network, but also misunderstandings and miscommunication between patients and their families. ${ }^{29}$ Finally, the variability in nephrologists' opinions and their preferences regarding medical, psychosocial, and behavioral considerations might partially account for the disparity in access to kidney transplantation, as might patients' sociodemographic and education status. ${ }^{30}$ For example, a patient's racial background may influence the physician's thoughts concerning the patient's behaviors and likelihood of treatment success. ${ }^{31}$

We found similar transplant survival rates across the different racial groups, which is in line with findings from studies conducted in the French and Canadian adult RRT population. These also reported similar transplant survival rates between patients of African descent and their white counterparts. ${ }^{32,33}$ However, studies including children, adolescents, and young adults with ESRD from the United States showed differences in transplant failure rates between racial groups. Chavers et $\mathrm{al}^{34}$ evaluated 13,692 US patients aged $<19$ years with a functioning kidney transplant in 1980 to 2004. After adjusting for multiple covariates, the transplant failure rate among African Americans was about 2-fold higher than for white patients during the entire study period. It has been suggested that this difference between the United States and other countries could be explained by a lack of universal access to health care in the United States, particularly to immunosuppressive drug coverage. However, a more recent study conducted in the United States found that even after adjusting for poverty level and insurance status, transplant survival rates were worse among black recipients compared with white patients. ${ }^{35}$

In terms of mortality risk on RRT, we found that Asian patients had a more than 2 times higher mortality risk compared with white patients. Adjustment for primary renal disease reduced the effect of racial background, suggesting that part of this effect may be 
explained by differences in the underlying kidney disease between racial groups. This is in line with data from a large study from the United States of 23,401 children and adolescents with ESRD, which also found primary renal disease to be independently associated with mortality risk. ${ }^{36}$ Our findings are in contrast to results from a recent study conducted in New Zealand. ${ }^{25}$ That study found high survival rates in Asian children on RRT, even comparable to their European counterparts. However, the study included too few Asian patients $(\mathrm{n}=12)$ for meaningful subanalysis.

Asian patients spent a longer period on dialysis treatment due to the reduced access to (living) kidney transplantation, which may have led to a higher risk for death. ${ }^{1,2}$ Based on this theory, we had expected higher mortality risk in black patients as well. However, in contrast to data from the United States, ${ }^{36}$ we did not find statistically significantly different mortality rates between white and black patients. Possibly, the relatively low mortality rates reported among black dialysis patients compared with their white counterparts in the adult ESRD population are also present among children with ESRD. ${ }^{37}$

Our study has several strengths, including the involvement of many countries in Europe, relatively long follow-up, and the distinction of 4 different racial groups. In addition, we used a competing-risk approach for the analysis of access to transplantation from a living kidney donor to take into account the influence of competing events (ie, transplantation from a deceased donor and death). However, there are also some limitations. First, the number of patients from minority groups in our study was relatively small and unequally distributed across countries. We attempted to adjust for these inequalities by correcting for country of residence in multivariate analyses. Second, data for racial background were missing for $22.8 \%$ of patients, which, given the differences found between outcomes of patients with and without data for racial background, may induce selection bias. To further investigate the identified disparities, the collection of data about racial background and socioeconomic status should therefore be strongly encouraged in registries. In addition, because we only included data from medium- and high-income countries, our results might not be generalizable to all European countries. Also, because data for racial background were reported by the renal units, we cannot exclude differences in coding systems for racial background used by national renal registries. Finally, although our registry includes a comprehensive set of clinical parameters, information for blood group and HLA profiles and data for socioeconomic status were not available for a sufficient number of patients. As a result, we were not able to disentangle biological effects other than primary renal disease (eg, blood group and genotype) from socioeconomic aspects of racial background.

In conclusion, we found important differences in access to transplantation and overall mortality on RRT among children, adolescents, and young adults with ESRD in Europe, with less favorable outcomes for black and Asian patients. Known biological aspects of racial background such as primary renal disease explained this disparity only partially, making it likely that other biological and socioenvironmental aspects are involved. The complex interactions between biological and socioenvironmental factors should be better studied to direct the targeted interventions so that this disparity can be reduced across racial subgroups. Although some racial disparities, such as mismatches with deceased donor kidneys and type of kidney diseases, may be unavoidable, interventions that improve preemptive and living donor transplantation are called for, especially in racial minority groups. In addition, further research is required to identify and address the contribution of medical and sociocultural barriers to preferred treatment among these groups.

\section{ACKNOWLEDGEMENTS}

We thank the members of the ESPN/ERA-EDTA Registry study group, R. Coppo, D. Haffner, J. Harambat, and C. Stefanidis (committee) and D. Shtiza, R. Kramar, R. Oberbauer, S. Baiko, A. Sukalo, K. van Hoeck, F. Collart, J.M. des Grottes, D. Pokrajac, D. Roussinov, D. Batinić, M. Lemac, J. Slavicek, T. Seeman, K. Vondrak, J.G. Heaf, U. Toots, P. Finne, C. Grönhagen-Riska, C. Couchoud, M. Lasalle, E. Sahpazova, N. Abazi, N. Ristoka Bojkovska, G. von Gersdorff, C. Scholz, B. Tönshoff, K. Krupka, B. Höcker, L. Pape, N. Afentakis, A. Kapogiannis, N. Printza, G. Reusz, Cs. Berecki, A. Szabó, T. Szabó, Zs. Györke, E. Kis, R. Palsson, V. Edvardsson, B. Gianoglio, S. Maringhini, C. Pecoraro, S. Picca, S. Testa, E. Vidal, E. Verrina, A. Jankauskiene, B. Pundziene, V. Said-Conti, S. Gatcan, O. Berbeca, N. Zaikova, S. Pavićević, T. Leivestad, A. Bjerre, A. Zurowska, I. Zagozdzon, C. Mota, M. Almeida, C. Afonso, G. Mircescu, L. Garneata, E.A. Molchanova, N.A. Tomilina, B.T. Bikbov, M. Kostic, A. Peco-Antic, B. Spasojevic-Dimitrijeva, G. Milosevski-Lomic, D. Paripovic, S. Puric, D. Kruscic, L. Podracka, G. Kolvek, J. Buturovic-Ponikvar, G. Novljan, N. Battelino, A. Alonso Melgar and the Spanish Pediatric Registry, S. Schön, K.G. Prütz, L. Backmän, M. Stendahl, M. Evans, B. Rippe, E. Maurer, G.F. Laube, S. Tschumi, P. Parvex, A. Hoitsma, A. Hemke, all centers participating in the RichQ study, R. Topaloglu, A. Duzova, D. Ivanov, R. Pruthi, F. Braddon, S. Mannings, A. Cassula, and M.D. Sinha for contributing data to the ESPN/ERA-EDTA Registry. This article was written by the authors on behalf of the ESPN/ERA-EDTA Registry, which is an official body of the ERA-EDTA.

We also thank the patients, their parents, and the staff of all the dialysis and transplant units that have contributed data by their national registries and contact persons; and Professor M.L. EssinkBot for advising us on the classification of racial background.

Support: The ESPN/ERA-EDTA Registry is funded by the ESPN and ERA-EDTA. This publication arises from the project of the ESPN/ERA-EDTA Registry (ESPN_FY2013), which has received funding from the European Union, in the framework of the Health Program. 
Financial Disclosure: The authors declare that they have no other relevant financial interests.

Contributions: Study concept and design: LAT, MN, KJvS, FS, JWG, KJJ; data acquisition: KJvS, CEK, AR, EAMC, CO'B, FP, FS, JWG, KJJ; data analysis/interpretation: LAT, MN, KJvS, CEK, AR, EAMC, CO'B, FP, FS, JWG, KJJ. Each author contributed important intellectual content during manuscript drafting or revision and accepts accountability for the overall work by ensuring that questions pertaining to the accuracy or integrity of any portion of the work are appropriately investigated and resolved. KJJ takes responsibility that this study has been reported honestly, accurately, and transparently; that no important aspects of the study have been omitted; and that any discrepancies from the study as planned have been explained.

\section{SUPPLEMENTARY MATERIAL}

Table S1: Demographic and clinical characteristics of incident patients with and without racial data.

Table S2: Association of racial group with access to transplantation in first $3 \mathrm{y}$ after initiating RRT in $\geq 2$-year-olds.

\section{REFERENCES}

1. Groothoff JW, Gruppen MP, Offringa M, et al. Mortality and causes of death of end-stage renal disease in children: a Dutch cohort study. Kidney Int. 2002;61:621-629.

2. McDonald SP, Craig JC. Long-term survival of children with end-stage renal disease. N Engl J Med. 2004;350:2654-2662.

3. Vogelzang JL, van Stralen KJ, Jager KJ, Groothoff JW. Trend from cardiovascular to non-cardiovascular late mortality in patients with renal replacement therapy since childhood. Nephrol Dial Transplant. 2013;28:2082-2089.

4. Kalantar-Zadeh K, Kovesdy CP, Derose SF, Horwich TB, Fonarow GC. Racial and survival paradoxes in chronic kidney disease. Nat Clin Pract Nephrol. 2007;3:493-506.

5. Reddan DN, Szczech LA, Klassen PS, Owen WF Jr. Racial inequity in America's ESRD program. Semin Dial. 2000;13: 399-403.

6. Powe NR, Melamed ML. Racial disparities in the optimal delivery of chronic kidney disease care. Med Clin North Am. 2005;89:475-488.

7. Epstein AM, Ayanian JZ, Keogh JH, et al. Racial disparities in access to renal transplantation-clinically appropriate or due to underuse or overuse? N Engl J Med. 2000;343:1537-1544, 1532.

8. Fan PY, Ashby VB, Fuller DS, et al. Access and outcomes among minority transplant patients, 1999-2008, with a focus on determinants of kidney graft survival. Am J Transplant. 2010;10: 1090-1107.

9. Furth SL, Garg PP, Neu AM, Hwang W, Fivush BA, Powe NR. Racial differences in access to the kidney transplant waiting list for children and adolescents with end-stage renal disease. Pediatrics. 2000;106:756-761.

10. Omoloja A, Stolfi A, Mitsnefes M. Racial differences in pediatric renal transplantation-24-year single center experience. J Natl Med Assoc. 2006;98:154-157.

11. Omoloja A, Mitsnefes M, Talley L, Benfield M, Neu A. Racial differences in graft survival: a report from the North American Pediatric Renal Trials and Collaborative Studies (NAPRTCS). Clin J Am Soc Nephrol. 2007;2:524-528.

12. Grace BS, Kennedy SE, Clayton PA, McDonald SP. Racial disparities in paediatric kidney transplantation. Pediatr Nephrol. 2014;29:125-132.
13. Schoenmaker NJ, Haverman L, Tromp WF, et al. Children of non-Western origin with end-stage renal disease in the Netherlands, Belgium and a part of Germany have impaired health-related quality of life compared with Western children. Nephrol Dial Transplant. 2014;29:448-457.

14. Schoenmaker NJ, Tromp WF, van der Lee JH, et al. Disparities in dialysis treatment and outcomes for Dutch and Belgian children with immigrant parents. Pediatr Nephrol. 2012;27:1369-1379.

15. Richter A, Kuhlmann MK, Seibert E, Kotanko P, Levin NW, Handelman GJ. Vitamin C deficiency and secondary hyperparathyroidism in chronic haemodialysis patients. Nephrol Dial Transplant. 2008;23:2058-2063.

16. World Bank Database. Available at http://www.worldbank. org. Accessed November 3, 2015.

17. van Stralen KJ, Tizard EJ, Verrina E, Schaefer F, Jager KJ. Demographics of paediatric renal replacement therapy in Europe: 2007 annual report of the ESPN/ERA-EDTA registry. Pediatr Nephrol. 2010;25:1379-1382.

18. van Stralen KJ, Verrina E, Belingheri M, et al. Impact of graft loss among kidney diseases with a high risk of posttransplant recurrence in the paediatric population. Nephrol Dial Transplant. 2013;28:1031-1038.

19. Andersen P, Geskus R, De witte T, Putter H. Competing risks in epidemiology: possibilities and pitfalls. Int J Epidemiol. 2012;41:861-870.

20. Noordzij M, Leffondre K, van Stralen KJ, Zoccali C, Dekker FW, Jager KJ. When do we need competing risks methods for survival analysis in nephrology? Nephrol Dial Transplant. 2013;28:2670-2677.

21. Jager KJ, Zoccali C, Macleod A, Dekker FW. Confounding: what it is and how to deal with it. Kidney Int. 2008;73:256-260.

22. Patzer RE, Amaral S, Klein M, et al. Racial disparities in pediatric access to kidney transplantation: does socioeconomic status play a role? Am J Transplant. 2012;12:369-378.

23. Patzer RE, Sayed BA, Kutner N, McClellan WM, Amaral S. Racial and ethnic differences in pediatric access to preemptive kidney transplantation in the United States. Am J Transplant. 2013; 13:1769-1781.

24. Samuel SM, Tonelli MA, Foster BJ, et al. Survival in pediatric dialysis and transplant patients. Clin J Am Soc Nephrol. 2011;6:1094-1099.

25. Grace BS, Kara T, Kennedy SE, McDonald SP. Racial disparities in pediatric kidney transplantation in New Zealand. Pediatr Transplant. 2014;18:689-697.

26. Tromp WF, Cransberg K, van der Lee JH, et al. Fewer preemptive renal transplantations and more rejections in immigrant children compared to native Dutch and Belgian children. Nephrol Dial Transplant. 2012;27:2588-2593.

27. Bratton C, Chavin K, Baliga P. Racial disparities in organ donation and why. Curr Opin Organ Transplant. 2011;16:243-249.

28. Shilling LM, Norman ML, Chavin KD, et al. Healthcare professionals' perceptions of the barriers to living donor kidney transplantation among African Americans. J Natl Med Assoc. 2006;98:834-840.

29. Ismail SY, Luchtenburg AE, Kal V, et al. Modifiable factors in access to living-donor kidney transplantation among diverse populations. Transplantation. 2013;96:586-590.

30. Tong A, Hanson CS, Chapman JR, et al. The preferences and perspectives of nephrologists on patients' access to kidney transplantation: a systematic review. Transplantation. 2014;98(7): 682-691.

31. van Ryn M, Burke J. The effect of patient race and socioeconomic status on physicians' perceptions of patients. Soc Sci Med. 2000;50:813-828. 
32. Pallet N, Thervet E, Alberti C, et al. Kidney transplant in black recipients: are African Europeans different from African Americans? Am J Transplant. 2005;5:2682-2687.

33. Yeates K, Wiebe N, Gill J, et al. Similar outcomes among black and white renal allograft recipients. J Am Soc Nephrol. 2009;20:172-179.

34. Chavers BM, Snyder JJ, Skeans MA, Weinhandl ED, Kasiske BL. Racial disparity trends for graft failure in the US pediatric kidney transplant population, 1980-2004. Am J Transplant. 2009;9:543-549.
35. Patzer RE, Mohan S, Kutner N, McClellan WM, Amaral S. Racial and ethnic disparities in pediatric renal allograft survival in the United States. Kidney Int. 2015;87(3):584-592.

36. Mitsnefes MM, Laskin BL, Dahhou M, Zhang X, Foster BJ. Mortality risk among children initially treated with dialysis for end-stage kidney disease, 1990-2010. JAMA. 2013;309:1921-1929.

37. Kucirka LM, Grams ME, Lessler J, et al. Association of race and age with survival among patients undergoing dialysis. JAMA. 2011;306:620-626. 